\title{
STERNAPIS CAPILLATA SP. N. (ANNELIDA, POLYCHAETA)
}

(Recebido em 30/12/65)

\author{
E. Nonato \\ Instituto Oceanográfico da Universidade de São Paulo
}

\begin{abstract}
SYNOPSIS
The species here described is the first representative of the family Sternaspidae found in Brazilian waters.

Diagnosis - Sternaspis capillata sp. n. is a small species, not longer than $20 \mathrm{~mm}$ when fully distended. Oral segment well formed with a conspicuous prostomium. Setae of the anterior region strong, bent and spatulate, of metallic colour, golden. Eight median segments with little bundles of capillary setae. Ventral shield formed by two different plates, with no external visible sculpturing and covered by fine mud. Twenty bundles of setae emerge on each side under the shield, those of the eleventh pair four times longer than the nearest ones.

The branchial region is densely covered by very thin and long papillae, up to the margin of the ventral shield. The branchiae are 15 to 20 in number on each side and are not grouped in plates.

The family is considered by many authors as having only one cosmopolitan species S. scutata (Ranzani) 1817. The incomplete descriptions of the greater part of the 14 species mentioned in HARTMAN's "Catalogue" renders it difficult to appreciate their validity.

S. capillata sp. n. diverges from the species mentioned in Hartman's "Catalogue" by the number of setae of the anterior segments, by the exceptional development of setae of the $11^{\text {th }}$ posterior pair and by the presence of numerous, long, filiform papillae covering the branchial region.

I consider the species near to S. laevis Caullery 1944, described from Malasia and known only from its original description.
\end{abstract}

\section{MATERIAL}

O material aqui estudado é proveniente de dois pontos ao largo da costa do Brasil e foi identificado como pertencente à família Sternaspidae, pela primeira vez assinalada, assim, na costa atlântica da América do Sul.

Os espécimens foram coletados pelos Srs. Plínio Soares Moreira - Est. 2.65.6 (entre Ubatuba e a Ilha Vitória), prof. $52 \mathrm{~m}$, fundo de lama; e Henrique Rodrigues da Costa, Est. 1185 - Almirante Saldanha' (2350' $\mathrm{S}-44^{\circ} 00^{\prime} \mathrm{W}$, cêrca de $80 \mathrm{~km}$ ao largo da Ilha Grande), prof. $127 \mathrm{~m}$, fundo de lama.

Em ambas as estações, em mar aberto, a salinidade é alta, da ordem de $35 \%$.

O material das duas procedências é homogêneo, variando apenas o tamanho dos exemplares. Consideramos necessário descrevê-lo como uma espécie nova, tendo em conta sobretudo a insuficiência das descriçôes e a conseqüente singularidade que parece ser própria a alguns de seus caracteres.

Publ. ne 234 do Inst. Ocean. da USP.
Sternaspis capillata sp. $\mathrm{n}$.

Est. E.65.6 - 58 exemplares; Est. $1185-2$ exemplares

DiAgnose - Espécie pequena, não ultrapassando, em plena extensão, $20 \mathrm{~mm}$. Segmento bucal bem conformado, com prostômio conspícuo. Cerdas dos setígeros anteriores fortes, recurvas e espatuladas, de côr metálica, dourada. Oito segmentos medianos, providos de pequenos feixes de cerdas capilares. Escudo ventral formado por duas peças distintas, sem escultura, externamente perceptível e recoberto por partículas finas de lôdo. Sob o escudo, de cada lado, emergem 20 feixes de cerdas; as do $11 .^{\circ}$ par, cêrca de quatro vêzes mais longas do que as adjacentes. Região branquial, até a margem do escudo ventral, densamente recoberta por papilas muito finas e longas. Brânquias em número de 15 a 20 de cada lado, não agrupadas em placa.

DESCRIÇÃo - A maioria dos exemplares, que recebemos fixados em álcool a $70 \%$, tinha a região 
anterior invaginada, como é habitual na família. Quando, nessas condições, os animais têm o aspecto de uma oliva, exibindo, numa das extremidades, o escudo ventral, cercado de cerdas longas e as brânquias, mais ou menos ocultas, entre uma densa "pilosidade". A evaginação dos segmentos anteriores se processa fàcilmente, ao serem os animais comprimidos com cuidado.

Excetuados os dois feixes de cerdas de comprimento excepcional, na região do escudo e as longas papilas filiformes que recobrem a região posterior, S. capillata sp. n. assemelha-se, em seu aspecto macroscópico, às espécies já conhecidas (Figs. 1 e 2).

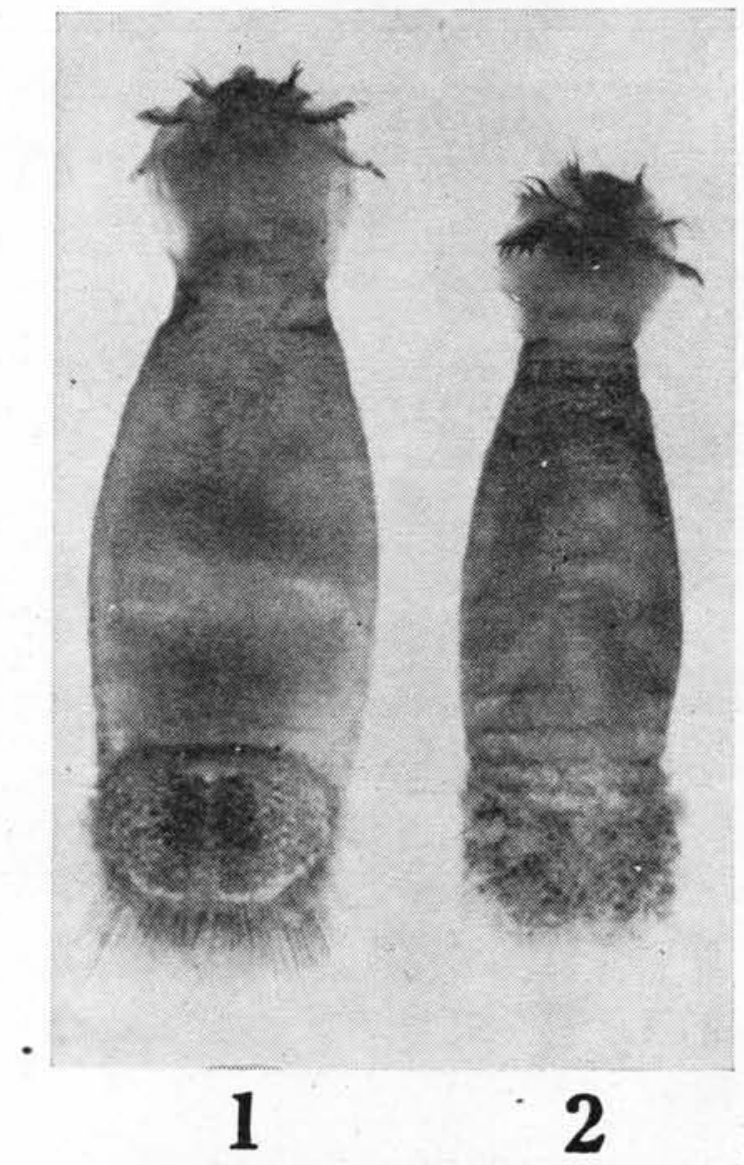

Figs. 1 e 2 - Sternaspis capillata sp. n. Vista ventral e dorsal; espécimens da região de Ubatuba.

A região posterior é formada, como em $S$. scuta. ta, por 7 segmentos, dos quais apenas o $2 .^{\circ}, 3 .^{\circ} \mathrm{e}$ $4 .^{\circ}$ são providos de cerdas. Estas são robustas, com o aspecto dos ganchos sigmóides de Pherusa (Figs. 3 e 4) e dispostas em fileiras semicirculares; a parte externa é curva, com secçâo fortemente elíptica, terminando em longa ponta afilada. Diferem das correspondentes de outras espécies, pela forma recurva e espatulada e pela ponta aguda, que é parte integrante da cerda e não acessória ou fàcilmente caduca. Cada uma das fileiras é constituída por 10 a 12 cerdas, cujo tamanho diminui gradualmente em direção à face yentral, sendo as últimas muito pe- quenas e finas (Fig. 5). Um exame superficial revela apenas as maiores, de côr metálica brilhante e, geralmente, em número de 8 a 9 em cada série.

A superfície dos 6 segmentos anteriores e de parte do $70^{\circ}$ é recoberta por papilas cônico-arredondadas, não aglutinando areia (Fig. 5, P).

O estrangulamento que precede as papilas genitais, no $70^{\circ}$ segmento, e que limita normalmente a parte invaginável, é bem marcado. As papilas genitais são longas, cilíndricas e recobertas por minúsculos grãos de areia.

Região mediana formada por oito segmentos, desprovidos de parapódios, porém dotados de um par de pequenos feixes de cerdas finíssimas. Pequenas papilas cilíndricas, esparsas, recobrem tôda a região. Como em algumas espécies de Pherusa, estas papilas aglutinam firmemente grãos de areia, dando um aspecto áspero ao corpo do animal. Nos 3 últimos segmentos, as papilas têm disposição mais ou menos ordenada, em fileiras transversais, constituindo "franjas" curtas.

Região posterior caracterizada pelo escudo ventral, pelas brânquias situadas dorsalmente em doris grupos e por tufos de filamentos longos e estreitos, lembrando uma cabeleira hirsuta.

O escudo aparece, geralmente, recoberto por uma fina camada de lôdo, difícil de afastar. Mesmo quando inteiramente limpo, não mostra qualquer escultura, sendo evidente apenas que é formado por duas peças simétricas, de contornos externos arredondados.

Examinado pela face interna, após dissecção, tem um aspecto completamente diverso, com os bordos crenulados e a superfície sulcada por estrias radiais (Fig. 6). A côr, imprecisa externamente, revela-se de um vermelho-alaranjado intenso.

Ao longo das estrias são perceptiveis zonas claras e transparentes, que correspondem, provàvelmente, a perfuraçōes da parte córnea (Fig. 7).

O tegumento, em volta do escudo, é também recoberto pelas papilas capilares, entre as quais emergem feixes radiais de cerdas rígidas, todos num mesmo plano.

Com exceção do $11 .^{\circ}$ par, os feixes são constituídos de maneira semelhante, por 3 a 5 cerdas aciculares, finas e retas, acompanhadas de algumas cerdas capilares.

O $11 .^{\circ}$ par contém 2 ou 3 cerdas, semelhantes às aciculares dos demais, porém, de comprimento cêrca de 4 vêzes maior; retas, finas e flexíveis, muito resistentes. (A maioria dos exemplares examinados as possui ainda pràticamente intactas).

As brânquias, longas e cilindricas, atingem a metade do comprimento do animal. A maioria delas aparece enrolada em espiral (Fig6. 8 e 9), destacando-se pela sua forma e diâmetro entre as papilas capilares que as cercam.

Uma "placa branquial" bem delimitada, como ocorre em S. scutata (Fauvel 1927, fig. 76; Ushakov 1955, fig. 131), não existe em $S$. capillata sp. n. As brânquias estão dispostas em filas irregu- 


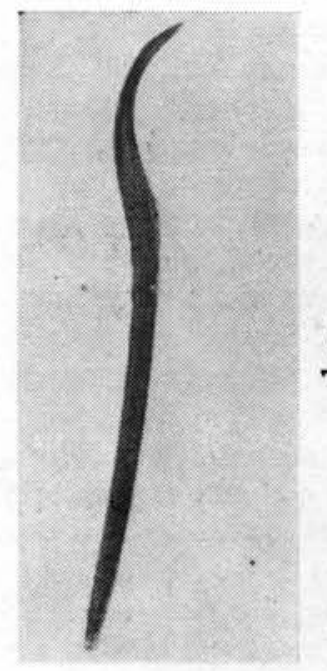

3

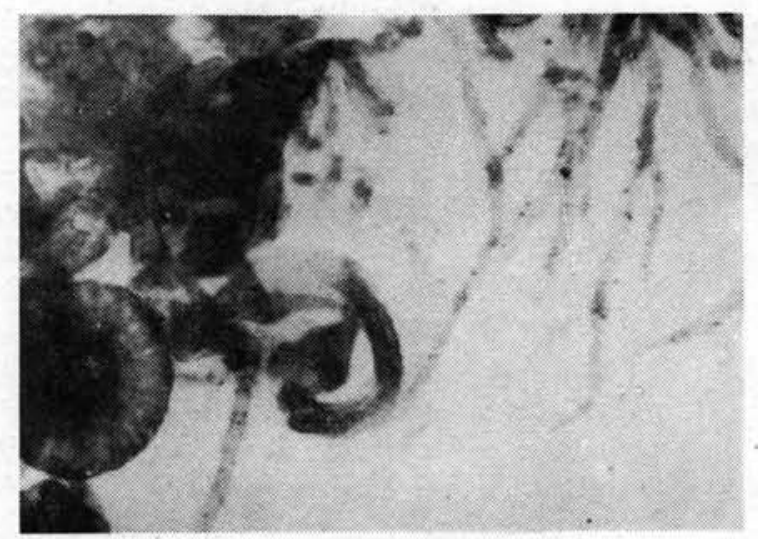

8

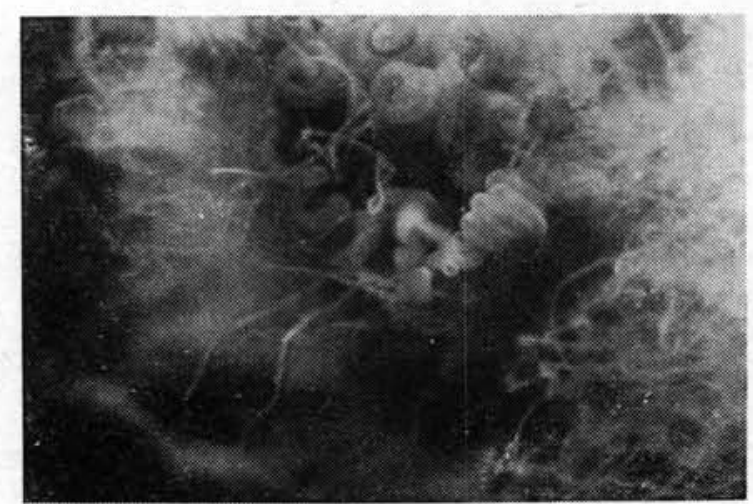

9

4
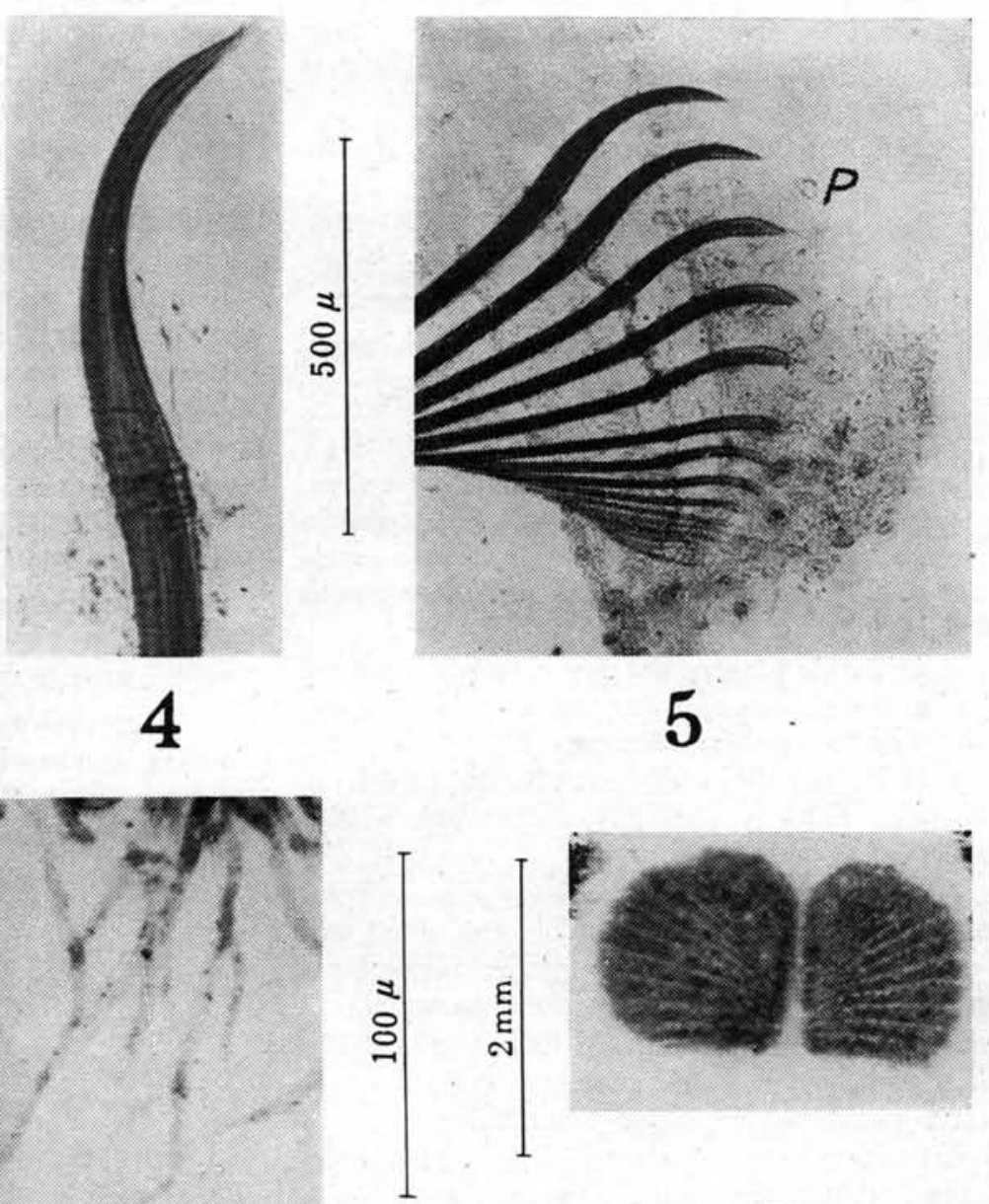

6

5
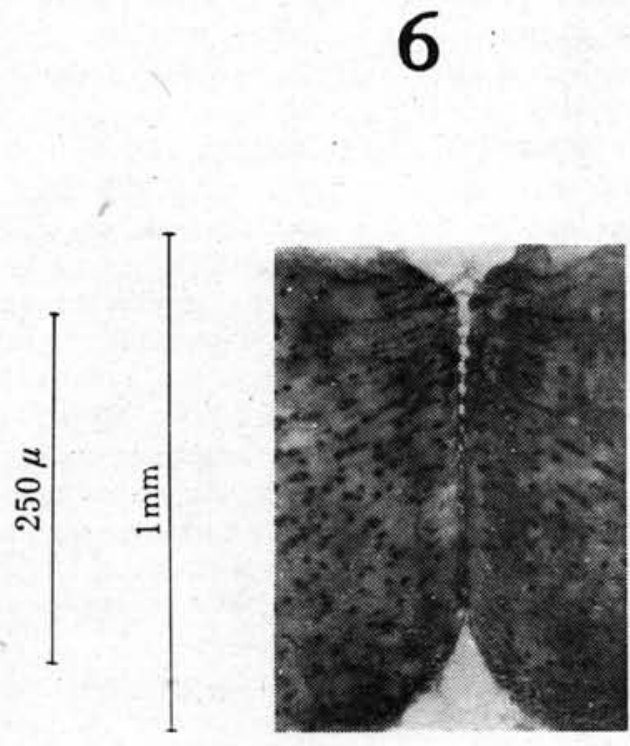

7

Fig. 3 - Cerda do 29 setigero.

Fig. 4 - Detalhe da extremidade de uma cerda de setigero anterior.

Fig. 5 - Série completa de cerdas do $2^{\circ}$ setigero; $p=$ papilas epidérmicas.

Fig. 6 - Escudo ventral, visto pela face interna.

Fig. 7 - Detalhe do escudo ventral, face interna, mostrando a zona fenestrada.

Fig. 8 - Brânquias e papilas capilares da região posterior; preparação comprimida, vista por transparência.

Fig. 9 - Detalhe da região posterior, mostrando brânquias e papilas. 
lares, nas margens externas da face dorsal dos últimos segmentos. Cada brânquia corresponde a uma perfuração da parede do corpo, perfeitamente visivel no exame pela parte interna.

Côr no álcool: cinza-amarelado; escudo de tonalidade mais escura.

Comprimento - Exemplares da região de Ubatuba: 5 a $12 \mathrm{~mm}$; exemplares do 'Almirante Saldanha': 18 a $20 \mathrm{~mm}$, com um diâmetro de $4,5 \mathrm{~mm}$.

Espécimens das duas procedências estão depositados no Museu do Departamento de Zoologia da Secretaria da Agricultura do Estado de São Paulo.

Discussão - Hartman (1959, p. 437) refere, para a família Sternaspidae, 14 espécies, considerando, porém, válidas apenas 2 delas. Mesmo estas, $S$. scutata e $S$. fossor são passíveis de interpretação contraditória. (1)

$\mathrm{Na}$ opinião de alguns autores existiria, mesmo, apenas uma espécie, cosmopolita, S. scutata (Ranzani) 1817. Assim o consideraram Fauvel (1927, p. 216 e 1953, p. 401-402), Pettibone (1954, p. 309), Tebble. (1955, p. 134-135) e Ushakov (1955, p. 352), entre outros.

As descrições por demais sucintas e a referência lacônica às espécies assinaladas em diferentes partes do mundo, tornam pràticamente inexeqüível uma comparação decisiva com o nosso material.

Mesmo o extenso estudo de Rietsch (1882) sôbre $S$. scutata, não é suficientemente explícito quan. to a certos caracteres de valor taxonômico.

Ainda assim, é possivel verificar certa semelhança entre alguns caracteres e aproximar a espécie atual de outras anteriormente descritas.

A única menção explícita a uma "pilosidade" dos segmentos posteriores, que encontramos, é a referente a Sternaspis laevis Caullery.

Caullery descreve (1944, p. 67-68, fig. 62) filamentos que se tornam muito longos nos últimos segmentos, especialmente em tôrno do escudo e em tôda a região branquial: "Là (na região branquial) ils forment un chevelu très fin, d'importance presque comparable aux branchies". Nesse particular, a descrição se aplica perfeitamente à espécie atual.

A forma e características externas do escudo ventral coincidem também. Quanto ao número de feixes de cerdas, em tôrno do escudo - apenas 15 pares em $S$. laevis - é um caráter de valor duvidoso; o próprio Caullery (p. 68) evidencia a dificuldade em distinguir alguns dêles.

Apesar dessa evidente semelhança, não cremos que as espécies sejam idênticas.

Em S. capillata as brânquias (Fig. 9) são perfeitamente distintas das papilas capilares; o diâmetro

(1) O tipo de Sternaspis scutata seria, para HARTMAN (1959, p. 437), Echinorhynchus scutatus Renier 1807 e nāo, como tem sido aceito pela generalidade dos autores, Thalassema scutatum Ranzani 1817. No bibliografia que pudemos consultar, não encontramos outra referência ao trabalho de RENIER (1807, Tavola per servire alla classificazione e conoscenza degli Animali. Padova, 8P., folio), mencionado pela autora, à p. 625 . muito maior e a forma cilíndrica, enrolada em espiral apertada, as torna inconfundíveis.

Em $S$. laevis, nem pela descrição, nem pela figura podemos discernir a relação entre brânquias e papilas; tampouco é claro o que quis dizer CAULleRY ao referir-se a uma cabeleira muito fina, de importância quase comparável às brânquias. Depreendemos, dessa parte da descrição, que $S$. laevis teria um número de brânquias muito superior aos 20 pares de $S$. capillata sp. n. ou, inversamente, que a "cabeleira" seria muito menos densa do que a desta última espécie.

Aparentemente, o número de brânquias, no gênero Sternaspis, pode ser muito grande; UshaKov (1955, fig. 131) figura cêrca de 90 de cada lado, para $S$. scutata.

De qualquer forma, é admissivel que, na espécie de Caullery, brânquias e papilas capilares tivessem aspecto muito semelhante.

A propósito, Chamberlain, ao caracterizar a família Sternaspidae, refere-se a "two dense bundles of long filamentous branchiae" (1919, p. 404-405) e na descrição de $S$. major (p. 406-407) menciona "Branchiae numerous, densely arranged and very fine".

Esta última afirmativa, indubitàvelmente, carece de valor, significando, provàvelmente, que o tipo, "badly broken", de $S$. major tenha perdido tôdas as brânquias, que são relativamente frágeis, restando apenas as papilas capilares!

Subsiste, entretanto, o fato de que papilas, delgadas e mais ou menos longas, existem em diversas espécies e teriam sido, por vêzes, confundidas com as brânquias verdadeiras.

No Atlântico sul era conhecida S. scutata, da costa oriental da África (Augener, 1918).

S. laevis foi descrita da Malásia e $S$. maior Chamberlain, do Gôlfo da Califórnia.

Não sendo possível o confronto entre o nosso material e o de CAUllery, preferimos considerá-lo como espécie nova, peculiar ao Atlântico sul-americano.

\section{R ES U M O}

Steruaspis capillata sp. n., aquí descrita, é o primeiro representante da família Sternaspidae a ser assinalado em águas brasileiras.

A familia é considerada, por muitos autores, como contendo apenas uma espécie, cosmopolita, S. scutata (Ranzani) 1817. A insuficiência das descrições torna difícil uma apreciação objetiva do valor das 14 espécies mencionadas no "Catálogo" de HARTMAN. Esta autora admite, como acêitáveis, duas espécies: S. scutata (Renier) 1807 e S. fossor Stimpson 1853. Destas, distingue-se $S$. capillata sp. n. pelo número e forma das cerdas dos segmentos anteriores, pelo excepcional desenvolvimento das cerdas do $11 .^{\circ}$ par posterior e pela presença de abundantes e longas papilas filiformes recobrindo a região branquial.

Consideramos a espécie próxima de $S$. laevis Caullery, 1944, descrita da Malásia e conhecida apenas através da descrição original. 
Augener, $\mathrm{H}$. 1918.

Polychaeta. Beitr. Kennt. Meeresfauna Westafr., vol. $2,2{ }^{\circ}$ fasc., p. $67-625,6$ pl.

Caullery, M.

1944. Polychètes sédentaires de l'Expédition du Siboga. Siboga-Expéd., vol. 24, 2 bis, p. 1-204, 157 figs.

Chamberlain, R. V.

1919.

The Annelida Polychaeta. Mem. Mus comp. Zool. Harv., vol. 48, p. 1-514, pl. $1-80$.

FAUVel, $\mathrm{P}$.

1927.

Polychètes sédentaires. Addenda aux Errantes, Archiannélides, Myzostomaires. Faune Fr., vol. 16, p. 1-494, 152 figs.

1953. Annelida. Polychaeta. The fauna of India, including Pakistan, Ceylon, Burma and Malaya. Allahabad, The Indian Press, xii +507 p., figs. 1-250.
HARTMAN, O.

1959. Catalogue of the polychaetous annelids of the world. Occ. Pap. Allan Hancock Fdn, n. 23,628 p.

Pettibone, M. H.

1954. Marine polychaete worms from Point Barrow, Alaska, with additional records from the North Atlantic and North Pacific. Proc. U.S. natn. Mus., vol. 103, p. 203-356, figs. 26-39.

RIETSCH, M.

1882. Etudes sur le Sternaspis scutata. Ann. sci. nat. zool., sér. 5, vol. 13, p. 1-84, pl. $18-23$.

TebBLe, N.

1955. The polychaete fauna of the Gold Coast. Bull. Br. Mus. nat. Hist., Zool., vol. 3, n. ${ }^{\circ} 2$, p. $61-148$, figs. 1-30.

Ushakov, P. V.

1955. Poliquetas dos mares do Extremo Oriente. Akad. Nak USSR. Opredeliteli po Fauna USSR, n. ${ }^{\circ} 56$, p. $1-145,164$ figs. (em russo). 